\title{
Driving Simulation Test for Evaluating Hazard Perception: Elderly Driver Response Characteristics
}

\author{
Risa Takahashi a, Masayoshi Kobayashi a ${ }^{* 1}$, Tsutomu Sasaki a, Yoshiharu Yokokawa a, \\ Hideya Momose b, Toshio Ohhashi c \\ a Division of Health Sciences, Graduate School of Medicine Shinshu University \\ b Nishizawa Electric Meters Manufacturing Co., Ltd. \\ c Department of Innovation of Medical Health Sciences Research
}

\section{ARTICLE INFO \\ Article history: \\ Received 23 June 2015 \\ Received in revised from \\ 1 July 2017 \\ Accepted 1 July 2017 \\ Available online 21 July \\ 2017}

Keywords:

Driving simulation tests

Hazard perception skill

Palmar sweating response

Skin potential reflex

Elderly drivers

\begin{abstract}
We created a driving simulation test for assessing drivers' hazard-perception skills by measuring their palmar sweating response (PSR), skin potential reflex (SPR), and ability to operate the steering wheel, accelerator, and brake. We recruited 52 elderly people who were aged $\geq 60$ years and were active drivers. These participants undertook the driving simulation test, and we measured their PSR, SPR, and device operation responses. PSR tended to be greater in hazard scenes that involved anticipation or complexity processes, suggesting the involvement of factors such as the participants' readiness to anticipate hazards and their emotional changes. SPR response was faster in hazard scenes that involved a surprise process. SPR response was faster than braking response, except in scenes where the participants had only a fleeting moment to react to the hazard, suggesting that SPR is a suitable evaluation index for hazard perception timing. Two participants were suspected of having decreased cognitive function according to the Mini-Mental State Examination. These individuals exhibited PSR and SPR responses that were not consistent with the hazard scenes, and they made errors in their operation of the driving simulator. These findings highlight the need to examine the impact of decreased cognitive function on hazard perception.
\end{abstract}

\section{Introduction}

In recent years, the number of car accidents involving the elderly has been increasing and this has become a problem that must be addressed by society. The cases of car accidents involving elderly drivers is usually considered to be a decrease in mental and physical functioning in such individuals. In addition, many researchers have highlighted the existence of a relationship between driving ability and both visual attentiveness and cognitive function (Stutts, Stewart, \& Martell, 1998; Anstey, Wood, Lord, \& Walker, 2005; Innes et al., 2007; Horikawa, Morizono, Koga, Horie, 2009; Ishimatsu, Miura, \&, Shinohara, 2010; Selander, Lee, Johansson, \& Falkmer, 2011; Anstey, Horswill, Wood, \& Hatherly, 2012). It is further known that in the early stages of Alzheimer's disease (AD), although individual differences are large, it is possible to continue driving for a relatively long period of time (more than a few years; Fox, Bowden,

*1 Corresponding author at: Department of Health Sciences, Graduate School of Shinshu University, 3-1-1 Asahi, Matsumoto, Nagano 390-8621, Japan. E-mail addresses: mkobaya@shinshu-u.ac.jp (M. Kobayashi) 
Bashford, \&, Smith 1997; Dubinsky, Stein, \& Lyons, 2000; Duchek et al., 2003; Ott et al., 2008; Hunt, Brown, \& Gilman, 2010). However, individuals with early AD demonstrate impaired on-road driving performance (Fox et al., 1997) and impaired simulated driving performance (Stein and Dubinsky, 2011) when compared to healthy controls. Thus, a screening test that enables the detection of drivers who are at a risk of having accidents is being sought (Lloyd et al., 2001; Breen, Breen, Moore, Bree, \& O’Neil, 2007).

Strategies to evaluate driving ability can be broadly divided into three categories: evaluation using neuropsychological tests, evaluation using driving simulators, and evaluation of driving skills on the road. As an example of a neuropsychological test, the Trail Making Test (TMT) may be used to measure attention, visual search capacity, information processing speed, and execution function (Toyokura et al., 1996; Stutts et al., 1998; Freund, Colgrove, Burke, \& McLeod, 2008; Horikawa et al., 2009). In the metaanalysis conducted by Devos et al. (2011), TMT was suggested to be effective as a screening test for assessing driving capability. Regarding the evaluation of elderly drivers, the Mini-Mental State Examination (MMSE) is often used to measure cognitive function (Fox et al., 1997; Freund et al., 2005, 2008). Fox et al. (1997) performed an on-road driving evaluation and neuropsychological examinations and medical tests that were standardized to the elderly suspected of AD. They suggested that the MMSE is an effective predictor of driving skills of the elderly. In contrast, it has also been suggested that only cognitive function tests alone, including the MMSE, cannot determine the driving capability of elderly individuals with early-stage dementia (Iverson et al., 2010). Regardless, the evaluation of driving ability using neuropsychological tests has limitations.

Driving simulation tests are also used to ascertain driving skills and have the advantage of allowing researchers to evaluate a driver's ability to operate the steering wheel, accelerator, and brake (Lee, Cameron, \& Lee, 2003a; Freund et al., 2005a, 2008b; Fildes, Charlton, Muir, \& Koppel, 2007; Stein and Dubinsky, 2011; Andrews and Westerman, 2012). Driving ability has been evaluated using a combination of desktop tests (TMT and MMSE) and driving simulation tests (Dubinsky et al., 2000; Duchek et al., 2003; Lee et al., 2003a, 2003b, 2003c; Freund et al., 2005, 2008; Fildes et al., 2007). To evaluate driver skill, it is necessary to assess hazard-prediction abilities and vehicle operation skills. Driving simulation tests are more realistic than desktop neuropsychological tests in these respects, and they are also cheaper and more efficient than evaluations of on-road driving (Lee, Lee, Cameron, \& Li-Tsang, 2003c). Therefore, driving simulation tests will be of increasing importance in traffic-safety promotion centers, wherein the elderly renew their driver's licenses, and in medical facilities wherein cognitive-function tests are conducted.

\subsection{Hazard-perception skills}

Hazard perception is the process of responding to dangerous events on the road that could lead to a traffic accident (Crundall et al., 2012b). It is defined as "the ability to read the road and anticipate forthcoming events" (McKenna, Horswill, \& Alexander, 2006). A Personal computer (PC) -based hazardperception test has already been developed and used in the UK and Australian driver licensing systems. In this hazard-perception test, operating a simulated vehicle is not required, and therefore subjects can concentrate on identifying hazard scenes from video clips. In the PC-based hazard-perception test, since all subjects encounter the same hazard scenario, it is possible to objectively evaluate responses to the hazard. However, when compared with an on-road test, the hazard-perception test has limitations, such as lower realism, reduced field-of-view, and the inability to measure device operation (Wetton, Hill, \& Horswill, 2011).

Hazard perception (HP) is associated with processes such as "anticipation," "surprise," and "complexity" (Sagberg and Bjørnskau, 2006; Crundall et al., 2012b). Anticipation refers to the ability to infer the future occurrence of a hazard. In the research evaluating anticipation capacity, video clips taken from the driver's perspective have been used, and gaze and reaction time during the simulated driving have been evaluated (Sagberg and Bjørnskau, 2006; Borowsky et al., 2010; Crundall, Crundall, Clarke, \& Shahar, 2012a; Crundall et al., 2012b; Lehtonen, Lappi, Kotkanen, \& Summala, 2013; Meir et al., 2014) . Young novice drivers are more prone to crash because their skills of hazard prediction are worse than those of experienced drivers (Garay, Fisher, \& Hancock, 2004; Smith, Horswill, Chambers, \& Wetton, 2009). However, a video clip that suddenly presents the hazard of a volleyball in front of the vehicle has the potential to surprising both novice and experienced drivers; this event cannot be predicted. Moreover, in this case, young novice drivers may show faster reaction times than experienced drivers (Gottsdanker, 1982). Concept of complexity is concerned with the driver's ability to monitor multiple sources of potential threat in a complex and dynamic environment (Sagberg and Bjørnskau, 2006; Crundall et al., 2012b). In 
situations where it is necessary to pay attention simultaneously or sequentially to a plurality of hazards, effective visual search is required of the driver. In young novice drivers, the ability to pay attention to multiple potential risks may be less developed than in experienced drivers.

In the case of the elderly drivers, it has been suggested that self-evaluation of hazard-perception skill is related to self-regulation of driving (Horswill, Antsey, Hatherly, Wood, \& Pachana, 2011). For this reason, in an elderly driver, feelings of anxiety and decreased self-confidence (Gwyther \& Holland, 2012), as well as discomfort (Meng \& Siren, 2012) are emphasized.

\subsection{Biological indicators that reflect hazard-perception skills}

Palmar sweating response (PSR) and electrodermal activity (EDA) can be observed when people feel they are in danger or are surprised. PSR is also referred to as mental sweating or emotional sweating (Kuno, 1956). PSR can be caused by tension or emotional excitement, and it can also be promoted by higher nervous activity, such as that induced by mental arithmetic. Furthermore, PSR instantly occurs when people "stand ready," such as when they are suddenly approached by a stranger or presented with a challenge (Ogawa, 1975; Kobayashi, Tomioka, \& Ushiyama, \& Ohhashi, 2003). PSR also reflects skin sympathetic nerve activity, which is modified by the cerebral cortex, although the main mechanism is closely related to the cerebral limbic system (Ogawa, 1993; Homma, Nakahima, Toma, Ito, \& Shibata, 1998). In contrast, EDA reflects eccrine sweat gland activity, which can be broadly divided into skin potential activity (SPA) and skin conductance activity (SCA) based on the method of measurement (Learmonth, Ackerly, \& Kaplan, 1959; Martin and Venables, 1966; Venables and Martin, 1967). SPA is measured as skin potential reflex (SPR), whereas SCA is measured as galvanic skin response (GSR) or skin conductance response (SCR).

Taylor (1964) reported that GSR reflects an individual driver's level of emotional tension or anxiety caused by the task of driving. Helander (1978) measured the SCR of drivers and reported that there is a high correlation $(\mathrm{r}=0.95)$ between SCR during driving and brake pressure, with SCR occurring $0.2 \mathrm{~s}$ prior to the release of the accelerator and $1.9 \mathrm{~s}$ prior to braking. In a study by Crundall et al. (2003), using video clips of driving scenes, it was clear that police officers identified danger more rapidly, as evidenced by their exhibiting significantly higher SCR than beginner drivers. Kinnear et al. (2013) showed hazard perception video clips to three groups of drivers (learner drivers, beginner drivers, and highly experienced drivers) and compared their levels of SCR, as an indicator of their hazard perception. The SCR of highly experienced drivers was twice that of beginner drivers and three times that of learner drivers, which reveals that it is possible to develop hazard perception by gaining driving experience. These results demonstrate that PSR and EDA are appropriate indicators of driver hazard-perception.

\subsection{The current study}

We developed a PC-based prototype driving-simulator for evaluation of driver hazard-perception. Table 1 shows the components of the device. The steering wheel, accelerator, and brake pedal used in the driving simulator were all parts from actual vehicles in the market and appropriate resistance was produced through the use of springs for a real-world feel. Steering wheel, accelerator, and brake responses were derived by means of potentiometers along with output signals from a sweat meter (SKINOS SKN-2000) and skin potentiometer (SKINOS SPN-01). All data were simultaneously recorded by PC using an A/D converter.

In a test using this driving simulator, video footage of driving scenes was played on an LCD monitor while participants simulated driving. The video was taken using a high-definition camera installed on the dashboard of a vehicle, and the field of view of the video was approximately $90^{\circ}$.

There were two types of driving footage. One was a 6-min clip shot from inside a car of a drive through approximately $1.2 \mathrm{~km}$ of urban streets, while the other was a 5-min clip shot from inside a car of a drive through approximately $1.0 \mathrm{~km}$ of narrow streets in a residential area. The vehicle used for taking the footage had an automatic transmission, and it was driven at a maximum speed of $40 \mathrm{~km} / \mathrm{h}$ and with an average speed of approximately $12 \mathrm{~km} / \mathrm{h}$. The footage of the urban area included complex scenes such as "turning right at an intersection where a pedestrian was crossing the road." This scene could be categorized as providing complexity, as proposed by Sagberg and Bjørnskau (2006). The footage of the residential area included hazard-predictive scenes such as "a jogger approaches from the opposite direction" and/or "overtaking a moving bicycle." These scenes can be classified into the category of anticipation proposed by Sagberg and Bjørnskau (2006). A scene wherein a volleyball suddenly bounces from a side streets was 
also included in this footage. These scenes can be classified as surprise, as proposed by Sagberg and Bjørnskau (2006). At intersections, the sound of a turn indicator was heard while a flashing green arrow was simultaneously shown on the screen to help the participants predict the direction in which the car was about to turn (Figs. 2 and 4 ).

Table 1

The configuration of the driving simulator equipment

\begin{tabular}{|c|c|c|c|}
\hline $\begin{array}{l}\text { Video presentation \& } \\
\text { data recording }\end{array}$ & $\begin{array}{l}\text { Shuttle-PC } \\
\text { Platform } \\
\text { Video presentation } \\
\text { PC- speaker } \\
\text { Playback method } \\
\\
\text { Data recording }\end{array}$ & $\begin{array}{l}\text { Intel@ Atom D525 }(1.8 \mathrm{GHz}) \\
\text { Microsoft Windows } 7 \\
\text { Media player/27 inches LCD monitor } \\
\text { JBL Duet } \\
\text { Dedicated software: Synchronize the video } \\
\text { playback and data recording } \\
\text { Sampling rate can be set in } 1 \mathrm{~ms} \text { units }\end{array}$ & \\
\hline Steering wheel & $\begin{array}{l}\text { Product Name } \\
\text { Diameter } \\
\text { Rotation region } \\
\text { Reaction force } \\
\text { (Spring constant) } \\
\text { Signal conversion }\end{array}$ & $\begin{array}{l}\text { Tuner T-14 (MOMO) } \\
350 \mathrm{~mm} \\
360^{\circ} \times 2 \\
5 \mathrm{~N} / 90^{\circ}, 10.5 \mathrm{~N} / 180^{\circ}, 19.5 \mathrm{~N} / 270^{\circ} \\
25.2 \mathrm{~N} / 360^{\circ} \\
\text { Potentiometer }\end{array}$ & $\begin{array}{l}* 350 \mathrm{~mm} \\
* 360^{\circ} \times 3 \\
* 13 \mathrm{~N}\end{array}$ \\
\hline Accelerator & $\begin{array}{l}\text { Product Name } \\
\text { Reaction force } \\
\text { Signal conversion }\end{array}$ & $\begin{array}{l}\text { A190 Accelerator pedal (Mercedes Benz) } \\
14 \mathrm{~N} \text { (Maximum) } \\
\text { Potentiometer }\end{array}$ & $* 12 \mathrm{~N}$ \\
\hline Brake & $\begin{array}{l}\text { Product Name } \\
\text { Reaction force } \\
\text { Signal conversion }\end{array}$ & $\begin{array}{l}\text { A190 Brake pedal (Mercedes Benz) } \\
24 \mathrm{~N} \text { (Maximum) } \\
\text { Potentiometer }\end{array}$ & $* 22 \mathrm{~N}$ \\
\hline $\begin{array}{l}\text { PSR } \\
\text { SPR }\end{array}$ & $\begin{array}{l}\text { Sweat meter } \\
\text { Skin electrometer } \\
\text { Skin electrometer and } \\
\text { the driving simulator. }\end{array}$ & $\begin{array}{l}\text { SKINOS SKN-2000 } \\
\text { SKINOS SPN-01 } \\
\text { sweat meter were integrated and built into }\end{array}$ & \\
\hline External I/O & Input/output & $2 \mathrm{ch} / 2 \mathrm{ch}$ & \\
\hline
\end{tabular}

Note: $\mathrm{N}=$ newton

*Reference value of Toyota PRIUS

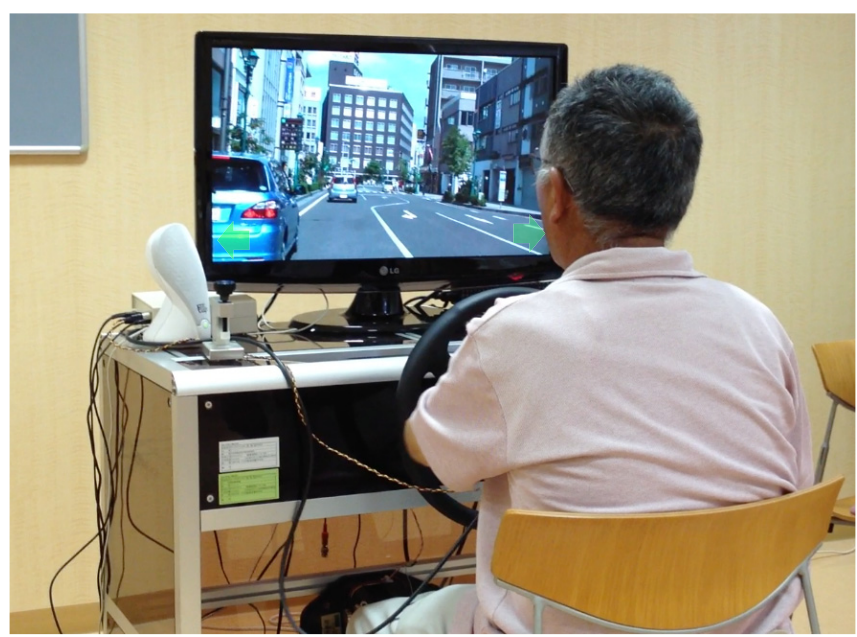

Fig.1. Driving simulation test 


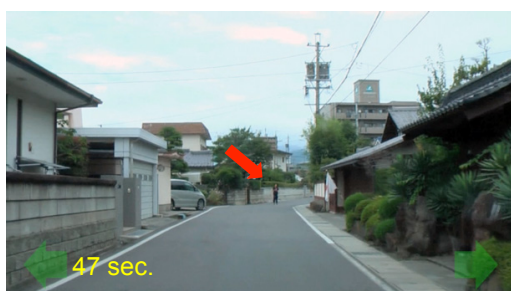

[A] Jogger approaches from the opposite direction

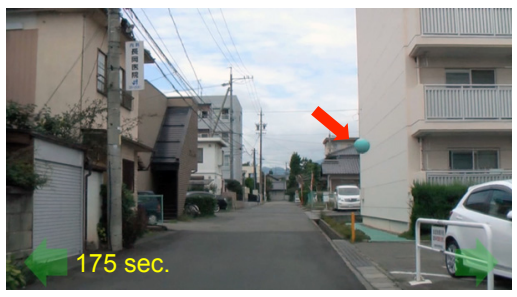

[D] Volleyball bounces in from a side street

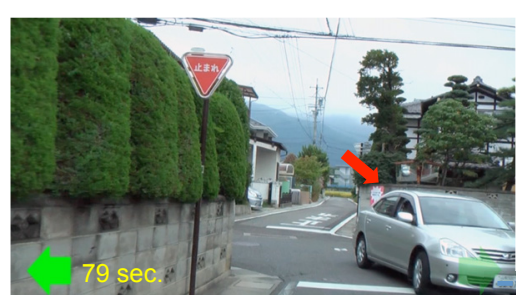

[B] Vehicle approaches from the opposite direction

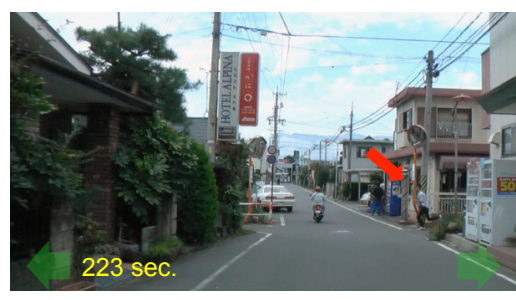

[E] Pedestrian runs out from a side street

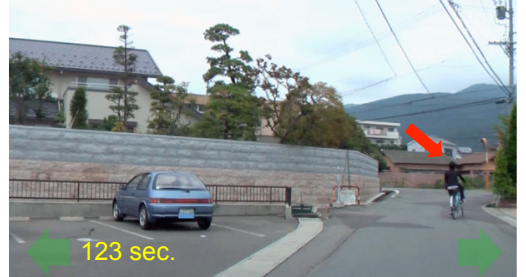

[C] Participant's vehicle overtakes a bicycle

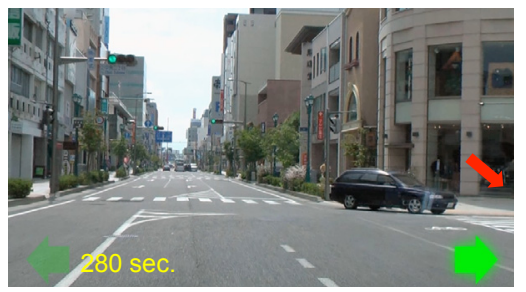

[F] Participant's vehicle turns right at an intersection

Fig. 2. Six scenes from the driving footage selected for analysis. Measurement start time of 10 seconds is displayed in the lower-left corner of the photo. The red arrow indicates the target hazard.

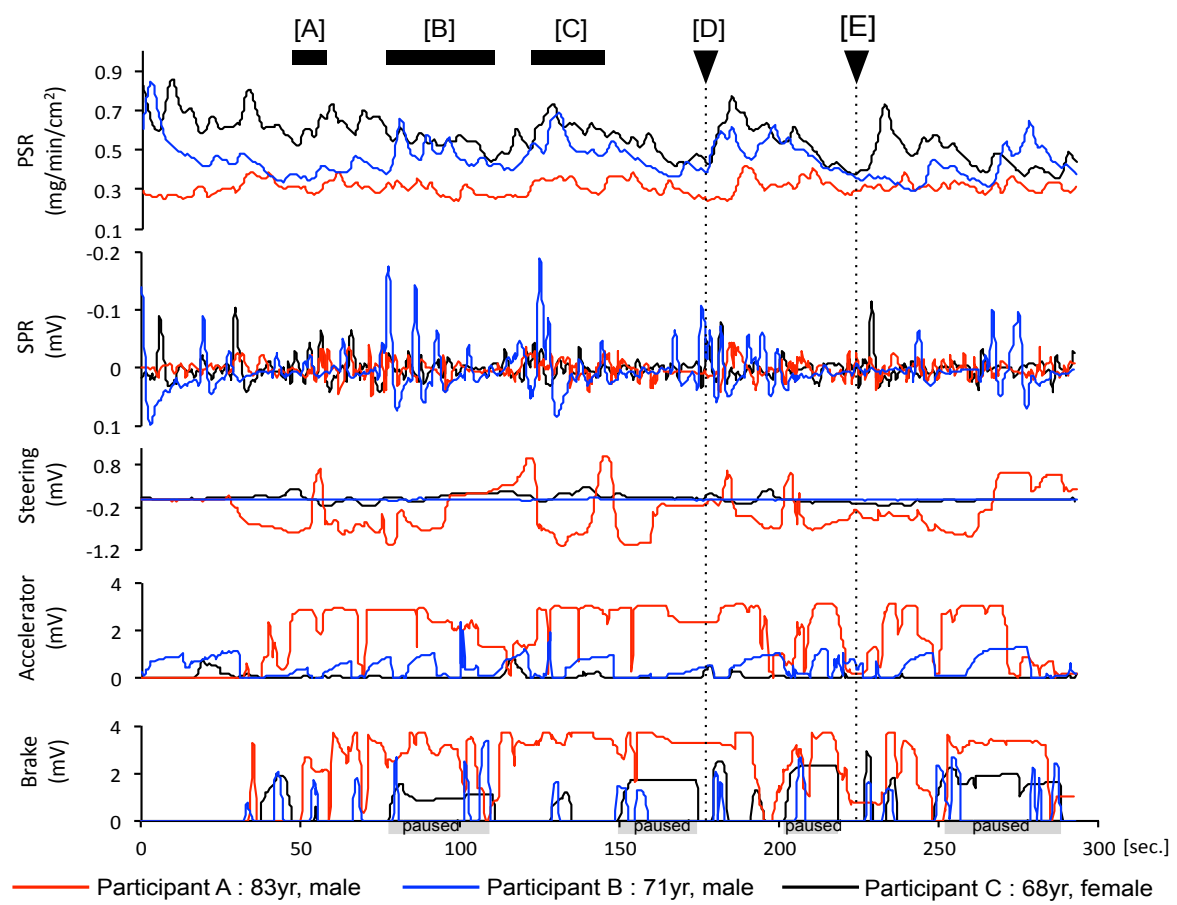

Fig. 3. Changes in PSR, SPR, and reaction volume of steering wheel, accelerator, and brake during driving simulation test. [A] Jogger approaches from the opposite direction, [B] Vehicle approaches from the opposite direction, [C] Participant's vehicle overtakes a bicycle, [D] Volleyball bounces in from a side street, [E] Pedestrian runs out from a side street.

This driving simulator has the advantage of using real driving footage rather than the computer graphics used in other driving simulators, which adds a sense of realism. However, steering wheel, accelerator, and brake operation do not correspond with the scene on the monitor. For example, turning the steering wheel does not change the direction of the footage shown on the screen. The video continues independently while 
the participant is required to simulate driving as the driver in the scene shown in the video. In this driving simulator, the use of realistic video is a novelty, and it is uniquely used to measure the PSR and SPR in order to assess hazard perception. However, this driving simulator dose not link the movement of the simulator controls to the vehicle motion, which is a limitation.

In a preliminary study using a prototype of the driving simulator, when the driver was surprised by a volleyball bouncing from a side street, the driver's eyes first moved to the volleyball. Immediately after that, the steering wheel was operated and the foot was removed from the accelerator and applied to the brake, after which SPR and PSR occurred (Kobayashi, Sasaki, Takahashi, \& Momose, 2014). This chain reaction of physical and physiological responses occurred within 1-2 s in cases where the participant tried to avoid the hazard, presumably because they were able to detect the hazard. However, in other scenes, the order of such reactions was not observed.

Since the PSR occurs when a person "is frightened," in the surprise hazard scene, it appeared that the response latency was short. In contrast, PSR is also induced in mental arithmetic and memory recall because of the influence of thought processes (Ogawa, 1993; Homma, et al., 1998; Homma, et al., 2001). This tends to occur in complex scenes and during prediction of hazards in scenes. In addition, elderly drivers with reduced cognitive functions do not know how to respond to this driving simulator. Therefore, we verified the relevance of PSR and SPR in hazard perception, via the following hypotheses.

(1) Reaction volume of PSR is greater in a complex scene and hazard prediction scene than surprise scene.

(2) Response latency of SPR is shorter in the scene wherein an individual is surprised.

(3) In participants with decreased cognitive functioning, PSR and SPR do not accord with the complexity or surprise inherent in a given scene.

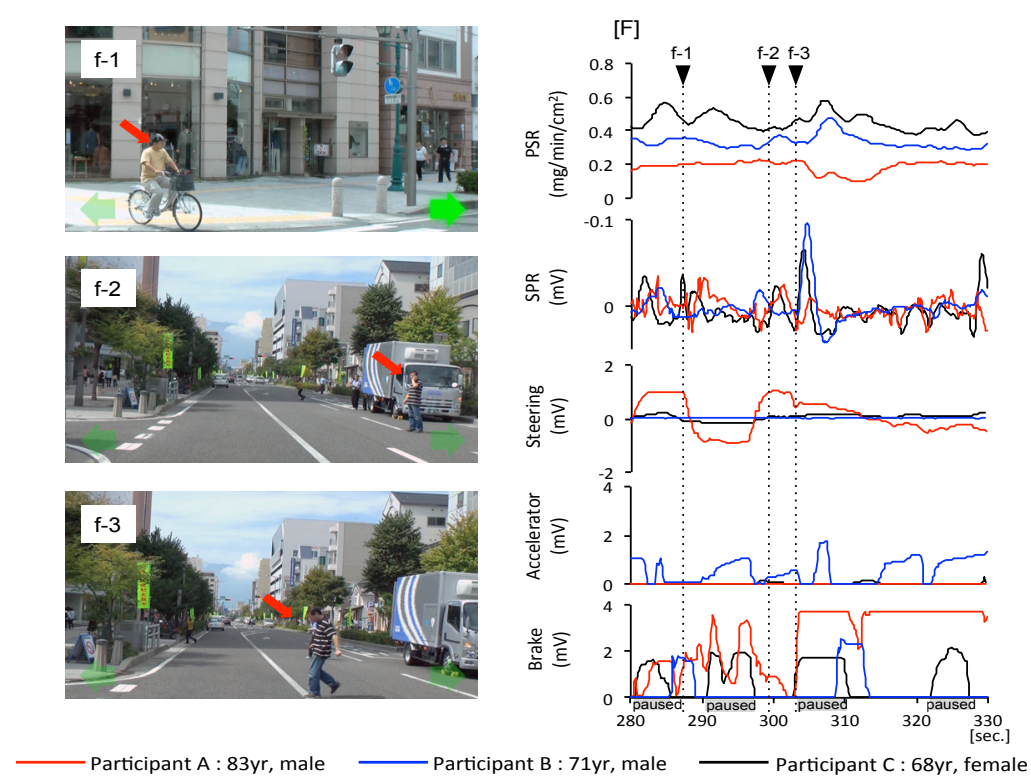

Fig. 4. Changes in PSR, SPR and reaction volume of steering wheel, accelerator, and brake when the participant's vehicle turned right at an intersection (continuation of scene $[\mathrm{F}]$ ).

Table 2

Hazard-scene classification

\begin{tabular}{ll}
\hline Classification & Driving scene \\
\hline Anticipation & {$[\mathrm{A}]$ Jogger approaches from the opposite direction } \\
& {$[\mathrm{B}]$ Vehicle approaches from the opposite direction } \\
& {$[\mathrm{C}]$ Participant's vehicle overtakes a bicycle } \\
\hline Surprise & {$[\mathrm{D}]$ Volleyball bounces in from a side street } \\
& {$[\mathrm{E}]$ Pedestrian runs out from a side street } \\
\hline Complexity & {$[\mathrm{F}]$ Participant's vehicle turns right at an intersection } \\
\hline
\end{tabular}




\section{Methods}

\subsection{Participants}

Participants were selected such that they could likely be experiencing a decline in their hazardperception skills due to age. The 52 participants who agreed to participate in this study consisted of 23 males and 29 females aged 60-85 years, with a mean age of $70.2 \pm 6.1$ years. They were selected from a group of elderly people aged $\geq 60$ years, who attended healthcare classes at the welfare park in Shiga, Matsumoto City. People who had no driver's license were excluded from the selection process. Shiga is situated in a mountainous region approximately $30 \mathrm{~min}$ by car from the Matsumoto city center. The healthcare classes are part of a preventive-care program regularly conducted by the government for the elderly.

\subsection{Functional measures}

The Japanese version of the MMSE and the TMT were used to evaluate the cognitive function and attentiveness of participants. The MMSE was developed by Folstein et al. (1975), and the Japanese version of the MMSE is widely used in Japan to measure the cognitive functions of the elderly. The maximum possible score on the MMSE is 30 points, whereas 27-30 points is considered normal, 21-26 points indicates a minor degree of cognitive impairment, 11-20 points indicates a moderate degree of cognitive impairment, and 0-10 points indicates severe cognitive impairment; the cut-off score that determines cognitive impairment is considered to be 23 points (Folstein, Folstein, \& Mchugh., 1975; Sugishita, Hemmi, \& Jadni, 2010). The Japanese version of the TMT is a two-part neuropsychological test used to evaluate factors such as attentiveness and visual search and execution capabilities. In Part A, a participant is required to draw a line between randomly placed numbers, ranging from " 1 " through " 25 ," in the correct order. In Part B, a participant is required to draw a line between randomly placed numbers ranging from " 1 " through "13" and circle Japanese letters ranging from “あ” to “し”; for example, “1” $\rightarrow$ “あ” $\rightarrow$ “2” $\rightarrow$ “い” $\rightarrow$ “3” $\rightarrow$ “う." TMT scores are determined by the time it takes to complete the test. The cut-off points for the Japanese version of TMT were used in this research (A4 size; horizontal $\times$ vertical $=297$ $\mathrm{mm} \times 210 \mathrm{~mm}$ ), namely $120 \mathrm{~s}$ for Part A and $150 \mathrm{~s}$ for Part B (Toyokura, Tanaka, Furukawa, \& Murakami, 1996).

\subsection{Questionnaire related to driving}

A questionnaire was configured to understand the driving experience and the self-evaluation of hazardperception skills (Horswill et al, 2011; Gwyther \& Holland, 2012; Meng \& Siren, 2012) of the participants. The questionnaire consisted of the following items. 1) How long has it been since you acquired your driver's license? 2) How often do you drive? 3) What do you use a vehicle for? 4) Have you caused an automobile accident during the past year? 5) Have you felt that your driving skills are deteriorating? 6) What situations do you find dangerous when driving (narrow street, wide street, intersection, railway crossing, driving in the rain, driving at night, traffic congestion, multiple lanes)? 7) What did you think of this driving simulation test (degree of difficulty)? Participants were requested to provide multiple answers to questions 3) and 6), as necessary. With regard to questions 4) and 5), participants were requested to answer "yes" or "no" and to provide specific examples.

\subsection{Experimental design}

According to the classification of hazard perception that Sagberg and Bjørnskau (2006) proposed (anticipation, surprise, complexity), the following six scenes from the driving footage were selected for analysis (Fig. 2): [A] Jogger approaches from the opposite direction; [B] Vehicle approaches from the opposite direction (participant's vehicle was stationary); [C] Participant's vehicle overtakes a bicycle; [D] Volleyball bounces in from a side street; [E] Pedestrian runs out from a side street; and, [F] Participant's vehicle turns right at an intersection. Scenes $[\mathrm{A}]$ through $[\mathrm{E}]$ were contained within the footage of the residential area with narrow streets, and $[\mathrm{F}]$ was in the urban area footage. Scenes $[\mathrm{A}]$ to $[\mathrm{C}]$ were classified into "anticipation," scene [D] and [E] were classified into "surprise," and the scene that required attending to more than one pedestrian [F] was classified into "complexity" (Table 2). 
To verify hypothesis (1), the response volume of PSR, SPR, and braking in scene [A] to [F] were compared as indicators of hazard prediction. In connection with hypothesis (2), response latency of SPR and braking for scenes [A] to [F] were compared. In addition, to explore hypothesis (3), each responses of participants with an MMSE score of $<23$ were compared with the responses of participants with an MMSE score of $\geqq 23$.

\subsection{Procedure}

The driving simulator prototype was installed in a training room at the welfare park. Each participant was individually tested in a quiet environment where the temperature and humidity were maintained at $24.8 \pm 1.2^{\circ} \mathrm{C}$ and $42.9 \pm 4.1 \%$, respectively, using an air conditioner. Each participant was asked to complete Japanese versions of the MMSE and TMT. A driving simulation test was conducted while the participant was sitting on a chair placed $60 \mathrm{~cm}$ in front of an LCD monitor. PSR was measured by attaching a sweat-meter probe to the palm side of the left thumb, and moisture volume per $1 \mathrm{~cm}^{2}$ was recorded using the ventilated capsule method (Ohhashi, Sakaguchi, \& Tsuda, 1998). SPR was measured by placing skin potentiometer electrodes on the left forearm and thenar regions, between which a base electrode was attached to create a bipolar lead.

An image of a participant taking the driving simulation test is shown in Figure 1. An initial simulation was conducted using a 5-min video prepared for practice purposes. After it was confirmed that the participant was able to operate the steering wheel, accelerator, and brake of the driving simulator, driving footage was shown at a sound pressure level of 50-60 dB. Footage from both an urban and from a residential area with narrow streets was shown to all participants, in a different order for each participant. Together with analogue signals from the steering wheel, accelerator, and brake, PSR and SPR were simultaneously recorded by the data analytical device during the simulation at a sampling frequency of 100 ms after A/D conversion. Following the completion of the driving simulation tests, participants were asked to complete a questionnaire regarding the driving simulation test and to provide a self-assessment of their driving skill. This study was approved by the ethics committee of the Shinshu University School of Medicine (Approval No. 2,073).

\subsection{Data analysis}

The average 10-s PSR and brake response levels were obtained based on the time recorded in situations [A] through [F] (Fig. 2). For SPR, the maximum amplitudes of negative waves that occurred after viewing [A] through [F] were measured. SPR reaction latency was defined as the time after viewing one situation (from any of scenarios [A] through [F]) to the start of the appearance of the first negative wave. In cases where the reaction started with a positive wave, the SPR reaction latency was defined as the time taken for the positive wave to turn into a negative wave.

The relationships between variables were analyzed using the Pearson product-moment correlation coefficient. Paired t-tests were used to compare SPR and braking reaction latency. One-way analysis of variance (ANOVA) and post-hoc tests (Bonferroni test) were used to compare responses in scene [A] through [F], with a significance level of $p<0.05$.

\section{Results}

\subsection{Summary of the questionnaire}

Of the participants, $42(81 \%)$ had $>30$ years of driving experience, while $31(60 \%)$ were expert drivers with $>40$ years of experience. Thirty-seven of the participants $(71 \%)$ drove almost every day and 10 (19\%) drove once every 2-3 days. The most common reason for using a vehicle, as indicated by 40 participants (77\%), was to go shopping followed by $26(50 \%)$ who used a vehicle to go to work, and 17 $(33 \%)$ who used a vehicle to pick someone up or take someone somewhere (multiple choice). Three of the participants had experienced minor car accidents within the past year. Thirty-four (65\%) of the participants felt that their driving skills had deteriorated, of whom six answered that they felt they had slow reactions, and four answered that they felt their attention was declining. When participants were asked when they sense danger (multiple choice), the most common answer, as indicated by 35 participants $(67 \%)$, was driving in the rain followed by $31(60 \%)$ who selected driving at night and $25(48 \%)$ who stated narrow streets, multiple lanes, and intersections. With regard to what they thought of the driving simulation test, 
$27(52 \%)$ responded that they thought it was "a little difficult" and 17 (33\%) said it was "difficult" (see Appendix).

\subsection{Summary of functional measures and results for participants A and B}

Participant age and gender as well as MMSE and TMT scores are shown in Table 3. MMSE scores and age showed a weak negative correlation $(\mathrm{r}=-.28, p<.05)$, while TMT Part-A had a medium degree of negative correlation with age $(\mathrm{r}=-.53, p<.01)$ and TMT Part-B had a strong negative correlation with age $(\mathrm{r}=-.72, p<.01)$.

Table 3

Summary of functional measures

\begin{tabular}{lccc}
\hline & $M(S D)$ & Participant A & Participant B \\
\hline Age & $70.19(6.09)$ & 83 & 71 \\
Male/Female & $23 / 29$ & Male & Male \\
MMSE (0-30, Cut-off: 23$)$ & $28.40(2.35)$ & 18 & 20 \\
TMT A (Cut-off: $120 \mathrm{~s})$ & $112.41(47.57)$ & 364 & Not completed \\
TMT B (Cut-off: $150 \mathrm{~s})$ & $154.46(80.75)$ & 586 & Not completed \\
\hline
\end{tabular}

Note. MMSE $=$ Mini Mental State Examination; TMT $=$ Trail Making Test $N=52$

The scores of two participants did not reach 23 points in MMSE (participants A and B in Table 3). Participant A (male, aged 83 years) had an MMSE score of 18 points (TMT Part A was $364 \mathrm{~s}$ and Part B was 586 s). Participant B (male, aged 71 years) had an MMSE score of 20 points (TMT Part A and Part B both could not be measured due to fatigue because the time to completion was greater than $10 \mathrm{~min}$ ). The mean score of the participants, including Participants A and B, for the MMSE was $28.4 \pm 2.4$ and for the TMT Part A and Part B was $112.4 \pm 47.6 \mathrm{~s}$ and $154.5 \pm 80.8 \mathrm{~s}$, respectively.

On the questionnaire, Participant A stated that he had obtained his driver's license $>40$ years ago and even now drove to go shopping almost every day. Although he had had no accidents within the past year, he was aware that his driving skills had deteriorated and that it was getting "difficult to see things." $\mathrm{He}$ also sensed danger at intersections and thought that the driving simulation test was difficult. Participant B also had $>40$ years of experience since acquiring his driver's license, and he drove almost every day in connection with his work. Although he had had no accidents within the past year, he sensed a deterioration in his driving skills and answered that he sensed danger at intersections and when driving in the rain. $\mathrm{He}$ also thought that the driving simulation test was difficult. Furthermore, he could not complete Parts A and $\mathrm{B}$ of TMT due to exhaustion.

\subsection{Responses of participants $A$ and $B$ to the driving simulation}

The response waves of participants $\mathrm{A}, \mathrm{B}$, and $\mathrm{C}$ obtained during the driving simulation are shown in Figure 3. Response waves for participant $\mathrm{C}$ (female, aged 68 years) were provided for comparative purposes; her MMSE score was the maximum possible (TMT Part-A was $100 \mathrm{~s}$ and Part-B was $118 \mathrm{~s}$ ). For participant C, increases in SPR negative waves and PSR were observed in situations [A] through [E] when the brake was applied. In particular, SPR amplitude and PSR level during scenes [D] and [E] increased remarkably. A decrease in both SPR negative wave and PSR was observed while the brake was applied in "paused" situations.

For participant A, SPR and PSR amplitudes were small, showing a tendency for a delayed response. An example of this pattern was seen for PSR in situation [D]. Furthermore, the amplitude of steering wheel, accelerator, and brake operation was extremely large. In fact, participant A stepped on both the accelerator and the brake at the same time in most situations. Although SPR amplitude was large for participant B and PSR displayed similar patterns of variation as participant $C$, in situation [E], hardly any increase in SPR negative wave or PSR level was observed. Furthermore, almost no steering wheel operation was observed and the accelerator was applied instead of the brake while at a temporary stop. 
Figure 4 shows the details of scene [F]. This situation began at $280 \mathrm{~s}$ as shown in the lower right photo in Figure 2. While the vehicle was turning right, a pedestrian appeared halfway through the turn and the vehicle repeatedly came to a temporary stop or drove slowly. Immediately after changing lanes (280 s) and prior to turning right, participant $\mathrm{C}$ produced SPR, PSR, and braking responses, after which more SPR, PSR, and braking responses occurred in response to the pedestrian (Fig. 4; f-1 - f-3). However, for participant A, no SPR or PSR was observed in response to the pedestrian, and participant B applied the accelerator in the scene while the vehicle was at a temporary stop.

\subsection{Reaction volume of PSR, SPR, and brake}

Average PSR, SPR, and braking reactions are shown in Table 4. A high level of PSR was observed in scenes $[\mathrm{A}],[\mathrm{B}],[\mathrm{C}]$, and $[\mathrm{F}]$; there were significant differences $(\mathrm{F}(5,255)=2.36, p=.04)$ when comparing situations [A] through [F]. Although the SPR negative wave was maximal in situation [F], there was no statistically significant difference when comparing situations $[\mathrm{A}]$ through $[\mathrm{F}]$. The braking response was the highest in $[\mathrm{A}]$ and $[\mathrm{D}]$, and there was a significant difference when comparing scenes $[\mathrm{A}]$ through $[\mathrm{F}]$ $(F(5,255)=11.64, p<.001)$. Post-hoc tests showed that the brake reaction volume was greater in scene [A] and [D] (see note to Table 4). In all situations [A] through [F], although a correlation was observed for reaction volume $(.30<|r|<.52)$, no correlation was observed between the reaction volumes of PSR and braking or between SPR and braking.

Table 4

Reaction volume of PSR, SPR, and braking

\begin{tabular}{|c|c|c|c|}
\hline & $\begin{array}{c}\mathrm{PSR} \\
\left(\mathrm{mg} / \mathrm{min} / \mathrm{cm}^{2}\right)\end{array}$ & $\begin{array}{l}\text { SPR } \\
(\mathrm{mV})\end{array}$ & $\begin{array}{c}\text { Braking } \\
(\mathrm{mV})\end{array}$ \\
\hline & $M(S D)$ & $M(S D)$ & $M(S D)$ \\
\hline [A] Jogger approaches from the opposite direction & $.42(.19)$ & $-.03(.35)$ & $1.30(1.03)$ \\
\hline [B] Vehicle approaches from the opposite direction & $.45(.19)$ & $-.05(.42)$ & $.97(.66)$ \\
\hline [C] Participant's vehicle overtakes a bicycle & $.45(.22)$ & $-.05(.40)$ & $.40(.81)$ \\
\hline [D] Volleyball bounces in from a side street & $.36(.17)$ & $-.05(.37)$ & $1.55(.85)$ \\
\hline [E] Pedestrian runs out from a side street & $.36(.16)$ & $-.02(.35)$ & $.79(.65)$ \\
\hline [F] Participant's vehicle turns right at an intersection & $.45(.22)$ & $-.17(.25)$ & $.76(.68)$ \\
\hline \multirow{2}{*}{ ANOVA } & 2.36 & 1.06 & 11.64 \\
\hline & $.04 *$ & 0.38 & $<.001 * *$ \\
\hline
\end{tabular}

Note. $N=52$.

SPR shows the average of the maximum value of the negative wave. The response volume of PSR and the SPR did not differ significantly in post-hoc tests comparing $[\mathrm{A}]$ through $[\mathrm{F}]$. In post-hoc tests (Bonferroni) of the response volume of braking, there were significant differences between $[\mathrm{A}]$ and $[\mathrm{C}] * *,[\mathrm{~A}]$ and $[\mathrm{E}] *,[\mathrm{~A}]$ and $[\mathrm{F}] *,[\mathrm{~B}]$ and $[\mathrm{C}]^{* *},[\mathrm{~B}]$ and $[\mathrm{D}]^{* *},[\mathrm{C}]$ and $[\mathrm{D}] * *,[\mathrm{D}]$ and $[\mathrm{E}] * *,[\mathrm{D}]$ and $[\mathrm{F}] * *$. $* p<.05, * * p<.01$

\subsection{Response latency of SPR and braking}

SPR and braking response latency were compared (Table 5). The fastest SPR was observed in scene [D] followed by $[\mathrm{F}],[\mathrm{E}],[\mathrm{C}],[\mathrm{B}]$, and $[\mathrm{A}]$. A significant difference was observed when comparing situations [A] through $[\mathrm{F}](\mathrm{F}(5,255)=2.36, p=.04)$. However, there was no significant difference in the post-hoc comparisons of $[\mathrm{A}]$ through [F]. The fastest braking response was observed in [D] followed by [A], [E], $[\mathrm{F}],[\mathrm{B}]$, and $[\mathrm{C}]$; a significant difference was observed when comparing situations $[\mathrm{A}]$ through $[\mathrm{F}](\mathrm{F}$ $(5,299)=25.74, p<.01)$. Post-hoc tests revealed that a significant difference was present between each scene (see note to Table 5). SPR occurred sooner than braking in situations [B] $(p=.003),[\mathrm{C}](p<.001)$, $[\mathrm{E}](p=.08)$, and [F.] $(p=.03)$, while the braking response was faster in situations $[\mathrm{A}](p=.04)$ and [D] $(p$ $=.07)$. With regard to scenario $[\mathrm{F}]$, a correlation was observed between SPR response latency and age ( $\mathrm{r}$ $=.46, p<.01)$, as well as between SPR response latency and TMT Part-A scores $(\mathrm{r}=.45, p<.01)$, while a weak correlation was observed between SPR response latency and TMT Part-B scores $(\mathrm{r}=.29, p<.05)$. No correlation was observed between SPR response latency and braking in any situations [A] through [F]. 
Table 5

Response latency of SPR and braking

\begin{tabular}{|c|c|c|c|}
\hline & SPR (s) & Braking (s) & \multirow[b]{2}{*}{$p$} \\
\hline & $M(S D)$ & $M(S D)$ & \\
\hline [A] Jogger approaches from the opposite direction & $2.08(1.53)$ & $1.29(2.52)$ & .04 \\
\hline [B] Vehicle approaches from the opposite direction & $2.05(1.73)$ & $3.61(2.90)$ & .003 \\
\hline [C] Participant's vehicle overtakes a bicycle & $2.05(1.24)$ & $7.97(4.42)$ & $<.001$ \\
\hline [D] Volleyball bounces in from a side street & $1.27(1.06)$ & $.81(1.57)$ & .07 \\
\hline [E] Pedestrian runs out from a side street & $1.93(1.41)$ & $2.94(3.85)$ & .08 \\
\hline [F] Participant's vehicle turns right at an intersection & $1.57(1.45)$ & $3.11(4.75)$ & .03 \\
\hline \multirow{2}{*}{ ANOVA } & 2.36 & 25.74 & \\
\hline & .04 & $<.001$ & \\
\hline
\end{tabular}

Note. $N=52$.

There were no significant differences in SPR response latency in post-hoc tests comparing [A] through [F]. Post-hoc tests (Bonferroni) of the response latency of braking revealed significant differences between [A] and $[\mathrm{B}]^{*},[\mathrm{~A}]$ and $[\mathrm{C}]^{* *},[\mathrm{~B}]$ and $[\mathrm{C}]^{* *},[\mathrm{~B}]$ and $[\mathrm{D}]^{* *},[\mathrm{C}]$ and $[\mathrm{D}]^{* *},[\mathrm{C}]$ and $[\mathrm{E}]^{* *},[\mathrm{C}]$ and $[\mathrm{F}]^{* *},[\mathrm{D}]$ and $[\mathrm{E}]^{* *}$, $[\mathrm{D}]$ and $[\mathrm{F}]^{* *}$.

$* p<.05 . * * p .01$

SPR and braking response latency for participants A and B are shown in Table 6. The fastest SPR for participant A was observed in scene [B] and the slowest was observed in [D]. Regarding the braking response, in situations other than $[\mathrm{F}]$ and $[\mathrm{A}]$, the brake had already been applied within the time frame, as shown in Figure 2. For participant B the fastest braking response was observed in scene [C] and the slowest was observed in scene [E]. Regarding the braking response, there was a tendency to be slow in all situations other than [B] and [C], and in scene [B] the brake had already been applied as it had been by participant A.

Table 6

Response latency of SPR and braking for participant A and B

\begin{tabular}{|c|c|c|c|c|}
\hline & \multicolumn{2}{|c|}{ Participant A } & \multicolumn{2}{|c|}{ Participant B } \\
\hline & SPR (s) & Braking (s) & SPR (s) & Braking (s) \\
\hline [A] Jogger approaches from the opposite direction & 4.4 & 3.0 & 3.1 & 5.8 \\
\hline [B] Vehicle approaches from the opposite direction & 1.3 & 0 & .9 & 0 \\
\hline [C] Participant's vehicle overtakes a bicycle & 1.7 & 0 & .1 & 5.5 \\
\hline [D] Volleyball bounces in from a side street & 6.1 & 0 & 2.2 & 4.2 \\
\hline [E] Pedestrian runs out from a side street & 2.6 & 0 & 3.3 & 3.5 \\
\hline [F] Participant's vehicle turns right at an intersection & 1.7 & .4 & .7 & 5.7 \\
\hline
\end{tabular}

Note. Braking latency of "0" indicates that the participant was already depressing the brake when the hazard scenario occurred.

\section{Discussion}

\subsection{Functional measures and driving ability}

Although the MMSE was originally used to assess the severity of dementia, a low MMSE score is a powerful indicator that forecasts car accidents involving elderly drivers (Ball \& Owsley, 1991). However, it is difficult to draw any clear conclusions regarding the risk of accidents for people with scores approximating the MMSE cut-off point, and it has been noted that the MMSE is limited with respect to discrimination of driving ability (Odenheimer et al, 1994). The TMT is used to evaluate attentiveness, visual search, and information-processing speed and it has the highest correlation with driving aptitude among all neuropsychological tests (Crowe, 1998; Marshall et al., 2007; Devos et al., 2011). In particular, in Part-B of the TMT, because a change in logic is repeatedly required, the participant's cognition must be flexible. A strong correlation was confirmed between MMSE and TMT Part-B scores; thus, it is suggested that cognitive function in the elderly is related to the flexibility of their thinking. 
MMSE scores for participants A and B were below the cut-off level and a moderate degree of cognitive impairment was suspected in both cases. TMT results clearly showed a decline in attentiveness, visual search, information processing speed, and execution capabilities. However, in reality, both participants A and $\mathrm{B}$ had driven almost every day during the past year without causing any accidents. That participants A and $\mathrm{B}$ continue to drive safely suggests that neuropsychological testing is of limited utility for evaluating driving ability (Odenheimer et al, 1994; Fox et al, 1997; Freund et al, 2005; Siren \& Meng, 2012). Both participants A and B recognized the deterioration in their driving skills and stated in the questionnaire that they sensed danger at intersections and when driving in the rain. Although a decline in cognitive function was observed in both participants, introspective self-evaluation was maintained in both cases and selfregulation was evident in actions such as driving along routes that they were accustomed to and driving slowly in the rain (Gwyther et al, 2012; Meng \& Siren, 2012), which were behaviors that helped them avoid danger and continue driving.

\subsection{Evaluation indexes for hazard perception}

Reaction volume of PSR tended to be greatest in scenes [A], [B], [C], and [F]. These scenes were classified into anticipation and complexity in accordance with Sagberg and Bjørnskau's (2006) conceptual classification. In scenes [A], [B], and [F], several seconds elapsed before the participant's vehicle reached the target, as indicated with a red arrow in Figure 2. We assumed that during this interval the participants anticipated a hazard that might occur (in scene [B], the participant's vehicle was stationary during this interval). It is known that PSR rises when a person is in a state of anticipation or feeling tense or anxious (Ogawa, 1975; Kobayashi et al., 2003; Crundall et al., 2003). The PSR that the participants exhibited in scenes classified into anticipation or complexity might have reflected the influence of the participants' readiness to anticipate hazards and/or their emotional changes.

The response latency of SPR in scenes [D] and [E], which were classified into surprise, tended to be shorter compared to anticipation scenes. The hazard in scene [D] occurred when a volleyball bounced in from a side street. This element of surprise might have impacted the participants' braking reaction volume and response latency. In contrast, in scene [E], the participants had a more time to react to the hazard (a pedestrian running out from a side street); this scene lacked the major element of surprise that was present in scene [D]. SPR response latency was also short in scene [F], classified into complexity. The reason for this result may be that participants, who were experienced drivers, anticipated early on the potential danger at the intersection.

As shown in Table 5, hazard and SPR responses were faster than braking responses, except in scenes [A] and [D]. This implies that SPR is a suitable index for evaluating hazard perception timing. Furthermore, braking response latency varied widely by scene, denoting that it is difficult to use this index to judge perception of the hazard, except in scenes that involve instant, reactive braking, such as scene [D]. Regarding scene [A], it should be noted that since this scene was the first of the six scenes shown in Figure 2 , the brake operation might have been influenced by the participants' initial nervousness with respect to the driving simulation test.

\subsection{Hazard-perception skills of participant $A$ and $B$}

For participants whose cognitive function was normal, in situations where danger was expected or danger had to be avoided, SPR negative waves and PSR levels tended to increase at the same time the brake was applied (Figs. 3 and 4). This was also the case for participant C, who had the maximum possible MMSE score. Such responses may accompany hazard perception, which is reflected in physical and emotional tension. However, the responses of participants A and B differed from those of participant $\mathrm{C}$ in many aspects, as described below.

For participant A, SPR and PSR tended to be small, suggesting the possibility of either a decline in eccrine sweat gland function or epidermal cornification due to aging, or both. SPR and PSR also tended to be late, and a remarkable delay was observed in the scene where the volleyball bounced out from a side street, as shown in Table 6. In the volleyball scene or the scene where a pedestrian run out (scene [E]), although the driver was supposed to recognize the danger and brake, the braking response of participant A did not match the footage displayed, which suggests that the hazard was not accurately recognized. As shown in Figure 3 and 4, the movements of participant A when operating the steering wheel, accelerator, and brake were extremely large, and the brake and accelerator were simultaneously applied. This was clearly a mistake and may reflect the confused state of participant $\mathrm{A}$ at the time of the test. 
Characteristics observed in participant B included frequent, large negative waves in SPR, and frequent switching of the foot between the accelerator and brake (Figs. 3 and 4). However, as shown in Figure 3, no increases in SPR or PSR were observed in the scene where a pedestrian ran out, which leads us to suspect that the participant failed to perceive the danger in that scene. Moreover, participant B turned the steering wheel minimally, tended to brake late in dangerous scenes (Table 6), and applied the brake many times during temporary stops. These mistakes suggest that Participant B had difficulty in assessing situations.

\subsection{Limitations and future research}

The video footage of driving scenes used in the driving simulation test was obtained while driving normally along a comparatively narrow Japanese road. The video footage of driving scenes used in the driving simulation test can be replaced arbitrarily. However, the responses of PSR, SPR, and device operation to hazards are not fully determined. Therefore, to judge the appropriateness of responses, it is necessary to collect additional data from subjects of various ages for all video footage to be used, to determine the standard range of responses.

In this study, two participants were suspected of exhibiting decreased cognitive function; this represents a very small sample. Future studies of the impact of cognitive function on hazard perception in driving simulations should use larger sample sizes. Further, future research should examine the reliability and validity of this driving simulation test by assessing its relationship with the available PC-based hazardperception tests and on-road tests. In addition, Horswill et al. (2015) conducted a hazard-perception training intervention for drivers aged 65 and older, and reported that response time for hazard perception decreased significantly. Moreover, this training effect persisted for 3 months. The video-based driving simulation test we developed could be used for hazard-perception training of elderly people who have decreased hazard-perception skills.

\section{Conclusions}

We created a driving simulation test for assessing drivers' hazard-perception skills. During the test, we measured the PSR, SPR, and device operation responses of 52 elderly drivers. PSR tended to be greater in hazard scenes classified into anticipation and complexity, which suggests the participants' readiness to anticipate hazards and their emotional changes. SPR responses tended to be faster in surprise hazard scenes. SPR responses were faster than braking response, except in scenes where the participants had only a brief moment to react to the hazard. This suggests that SPR is a suitable index for evaluating hazardperception timing. Two participants were suspected of having decreased cognitive function according to the Mini-Mental State Examination. These individuals exhibited PSR and SPR responses that were not consistent with the hazard scenes, and they made errors in their operation of the driving simulator. These findings highlight the need to examine the impact of decreased cognitive function on hazard perception.

\section{Acknowledgments}

This research was financially supported by the Japan Society for the Promotion of Sciences (JSPS) KAKEN Grant Number 23300245. The cooperation of participants and staff of the healthcare classes at the welfare park in Shiga district was greatly appreciated. In particular, we thank the community health nurses Takizawa, Furuhata, and Aoki for their cooperation.

\section{Appendix}

Summary of the questionnaire related to car driving that participants responded to

\begin{tabular}{llc}
\hline Question items & Classification & $N(\%)$ \\
\hline 1) Years of experience as a driver & More than 40 years & $31(59.6)$ \\
& $30-39$ years & $11(21.2)$ \\
& $20-29$ years & $5(9.6)$ \\
& $10-19$ years & $5(9.6)$ \\
& Less than 10 years & $0(0.0)$ \\
2) Frequency to drive & & $37(71.2)$ \\
& Almost every day & $10(19.2)$
\end{tabular}


Once a week

Once a month

A few times a year

It scarcely

(Unentered)

3) The purpose of using a car (Multiple choice)

Shopping

$40(76.9)$

Commuting (work)

26(50.0)

Drop off and pick up

$17(32.7)$

$4(7.7)$

$49(94.2)$

$3(5.8)$

- The ride to the curb

- Inattentive (derailing)

- Collision

NO

$18(34.6)$

$34(65.4)$

- Slow reaction

- Attention decline

6

4

- Decreased visual acuity

- Dull sensation

- Field of view becomes narrower

- I cannot back the car

- Feelings became troublesome

- Get tired easily

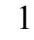

1

1

Driving of rainy weather

$35(67.3)$

Night driving

$31(59.6)$

Narrow road

25 (48.1)

Lane often road

25 (48.1)

$25(48.1)$

6(11.5)

6(11.6)

$1(1.9)$

Wide road

Easy

Little easier

$7(13.5)$

Usually

27(51.9)

Little difficult

17(32.7)

Note. $n=52$

\section{References}

Andrews, E.C., \& Westerman, S.J. (2012). Age differences in simulated driving performance: Compensatory processes. Accident Analysis and Prevention, 45, 660-668.

Anstey, K.J., Wood, J., Lord, S., \& Walker, J.G. (2005). Cognitive, sensory and physical factors enabling driving safety in older adults. Clinical Psychology Review, 25(1), 45-65.

Anstey, K.J., Horswill, M.S., Wood, J.M., \& Hatherly, C. (2012). The role of cognitive and visual abilities as predictors in the multifactorial model of driving safety. Accident Analysis and Prevention, 45, 766-774.

Ball, K., \& Owsley, C. (1991). Identifying correlates of accident involvement for the older driver. Human Factors. The Journal of the Human Factors and Ergonomics Society, 33(5), 583-95. 
Borowsky, A., Shinar, D., Oron-Gilad, T. (2010). Age, skill, and hazard perception in driving. Accident Analysis and Prevention, 42, 1240-1249

Breen, D.A., Breen, D.P., Moore, J.W., Breen, P.A., \& O’Neill, D. (2007). Driving and dementia. British Medical Journal, 334(7608), 1365-1369.

Crowe, S.F. (1998). The differential contribution of mental tracking, cognitive flexibility, visual search, and motor speed to performance on parts A and B of the Trail Making Test. Journal of Clinical Psychology, 54(5), 585-591.

Crundall, D., Chapman, P., Phelps, N., \& Underwood, G. (2003). Eye movements and hazard perception in police pursuit and emergency response driving. Journal of Experimental Psychology, 9(3), 163-174.

Crundall, D., Crundall, E., Clarke, D., \& Shahar A. (2012a). Why do car drivers fail to give way to motorcycles at t-junctions? Accident Analysis and Prevention, 44(1), 88-96.

Crundall, D., Chapman, P., Trawley, S., Collins, C., van Loon, E., Andrews, B. \& Underwood, G. (2012b). Some hazards are more attractive than others: Drivers of varying experience respond differently to different types of hazard. Accident Analysis and Prevention, 45, 600-609.

Devos, H., Akinwuntan, A.E., Nieuwboer, A., Truijen, S., Tant, M., De Weerdt, W. (2011). Screening for fitness to drive after stroke: A systematic review and meta-analysis. Neurology, 76(8), 747-756.

Dubinsky, R.D., Stein, A.C., \& Lyons, K. (2000). Practice parameter: risk of driving and Alzheimer's disease (an evidence-based review): Report of the quality standards subcommittee of the American Academy of Neurology. Neurology, 54(12), 2205-2211.

Duchek, J.M., Carr, D.B., Hunt, L., Roe, C.M., Xiong, C., Shah, K., \& Morris, J.C. (2003). Longitudinal driving performance in early-stage dementia of the alzheimer type. Journal of Experimental Psychology, 51(10), 1342-1347.

Fildes, B., Charlton, J., Muir, C., \& Koppel, S. (2007). Driving responses of older and younger drivers in a driving simulator. Annual Proceedings/Association for the Advancement of Automotive Medicine, 51, 559-572.

Folstein, M.F., Folstein, S.E., \& McHugh, P.R. (1975). "Mini-mental state.” A practical method for grading the cognitive state of patients for the clinician. Journal of Psychiatric Research, 12(3), 189-198.

Fox, G.K., Bowden, S.C., Bashford, G.M., \& Smith, D.S. (1997). Alzheimer's disease and driving: prediction and assessment of driving performance. Journal of the American Geriatrics Society, 45(8), 949-953.

Freund, B., Colgrove, L.A., Burke, B.L., \& McLeod, R. (2005). Self-rated driving performance among elderly drivers referred for driving evaluation. Accident Analysis and Prevention, 37(4), 613-618.

Freund, B., Colgrove, L.A., Petrakos, D., \& McLeod, R. (2008). In my car the brake is on the right: pedal errors among older drivers. Accident Analysis and Prevention, 40(1), 403-409.

Garay, L., Fisher, D.1., \& Hancock K.L. (2004). Effects of driving experience and lighting condition on driving performance. Human Factors and Ergonomics Society Annual Meeting Proceedings, Surface Transportation, 48, 2290-2294

Gottsdanker, R. (1982). Age and simple reaction time. Journal of Gerontology, 37, 342-348.

Gwyther, H., \& Holland, C. (2012). The effect of age, gender, and attitudes on self-regulation in driving. Accident Analysis and Prevention, 45, 19-28.

Helander, M. (1978). Applicability of drivers' electrodermal response to the design of the traffic environment. Journal of Applied Psychology, 63(4), 481-488.

Homma, S., Nakajima, Y., Toma, S., Ito, T., \& Shibata, T. (1998). Intracerebral source localization of mental process-related potentials elicited prior to mental sweating response in humans. Neuroscience Letters, 247(1), 25-28.

Homma, S., Matsunami, K., Han, X.Y., \& Deguchi, K. (2001). Hippocampus in relation to mental sweating response evoked by memory recall and mental calculation: a human electroencephalography study with dipole tracing. Neuroscience Letters, 305(1), 1-4.

Horikawa, E., Morizono, R., Koga, A., \& Horie, J. (2009). Elderly driving behavior and cognitive function Analysis of license renewal course data. IATSS Research, 33(1), 18-26.

Horswill, M.,S., Anstey, K.,J., Hatherly, C., Wood, J.M., Pachana, N.A. (2011). Older drivers' insight into their hazard perception ability. Accident Analysis and Prevention, 43, 2121-2127.

Horswill, M.,S., Falconer, E.,K., Pachana, N.,A., Wetton, M., Hill, A. (2015) . The longer-term effects of a brief hazard perception training intervention in older drivers. Psychology and Aging, 30 (1), 62-67.

Hunt, L.A., Brown, A.E., \& Gilman, I.P. (2010). Drivers with dementia and outcomes of becoming lost while driving. American Journal of Occupational Therapy, 64(2), 225-232.

Innes, C.R., Jones, R.D., Dalrymple-Alford, J.C., Hayes, S., Hollobon, S., Severinsen, J., Smith, G., Nicholls, A., \& Anderson, T.J. (2007). Sensory-motor and cognitive tests predict driving ability of persons with brain disorders. Journal of the Neurological Sciences, 260(1-2), 188-198.

Ishimatsu, K., Miura, T., \& Shinohara, K. (2010). Age influences visual attention characteristics among accident-free and accident-involved drivers. Japanese Psychological Research, 52(3), 186-200. 
Iverson, D.J., Gronseth, G.S., Reger, M.A., Classen, S., Dubinsky, R.M., \& Rizzo, M. (2010). Practice parameter update: evaluation and management of driving risk in dementia: report of the Quality Standards Subcommittee of the American Academy of Neurology. Neurology, 74(16), 1316-24.

Kinnear, N., Kelly, S.W., Stradling, S., \& Thomson, J. (2013). Understanding how drivers learn to anticipate risk on the road: A laboratory experiment of affective anticipation of road hazards. Accident Analysis and Prevention, 50, 1025-1033.

Kobayashi, M., Tomioka, N., Ushiyama, Y., \& Ohhashi, T. (2003). Arithmetic calculation, deep inspiration or handgrip exercise-mediated pre-operational active palmar sweating responses in humans. Autonomic Neuroscience, 104(1), 58-65.

Kobayashi, M., Sasaki, T., Takahashi, R., \& Momose H. (2014). Analysis of eye movements during drive simulator operation using the video recording. Poster session presented at the 16th World Congress of Occupational Therapists, Yokohama.

Kuno, Y. (1956). Human Perspiration. C.C. Thomas, Springfield, pp.103-109.

Learmonth, G.J., Ackerly, W., \& Kaplan, M. (1959). Relationships between palmar skin potential during stress and personality variables. Psychosomatic Medicine, 21(2), 150-157.

Lee, H.C., Cameron, D., \& Lee, A.H. (2003a). Assessing the driving performance of older adult drivers: on-road versus simulated driving. Accident Analysis and Prevention, 35(5), 797-803.

Lee, H.C., Lee, A.H., \& Cameron, D. (2003b). Validation of a driving simulator by measuring the visual attention skill of older adult drivers. American Journal of Occupational Therapy, 57(3), 324-328.

Lee, H.C., Lee, A.H., Cameron, D., \& Li-Tsang, C. (2003c). Using a driving simulator to identify older drivers at inflated risk of motor vehicle crashes. Journal of Safety Research, 34(4), 453-459.

Lehtonen, E., Lappi, O., Kotkanen, H., \& Summala, H. (2013). Look-ahead fixations in curve driving. Ergonomics, 56(1), 34-44.

Lloyd, S., Cormack, C.N., Blais, K., Messeri, G., McCallum, M.A., Spicer, K., \& Morgan, S. (2001). Driving and dementia: a review of the literature. Canadian Journal of Occupational Therapy, 68(3), 149-156.

Martin, I., \& Venables, P.H. (1966). Mechanisms of palmar skin resistance and skin potential. Psychological Bulletin, 65(6), 347-357.

Marshall, S.C., Molnar, F., Man-Son-Hing M, Blair, R., Brosseau, L., Finestone, H.M., Lamothe, C., KornerBitensky, N., \& Wilson, K.G. (2007). Predictors of driving ability following stroke: a systematic review. Topics in Stroke Rehabilitation, 14(1), 98-114.

McKenna, F.P., Horswill, M.S., Alexander, J. (2006). Does anticipation training affect drivers' risk taking? Journal of Experimental Psychology: Applied, 12 (1), 1-10.

Meir, A., Borowsky, A., Oron-Gilad, T. (2014), Formation and Evaluation of Act and Anticipate Hazard Perception Training (AAHPT) intervention for young novice drivers. Traffic injury prevention, 15(2), 172-80.

Meng, A., \& Siren, A. (2012). Cognitive problems, self-rated changes in driving skills, driving-related discomfort and self-regulation of driving in old drivers. Accident Analysis and Prevention, 49, 322-329.

Odenheimer, G.L., Beaudet, M., Jette, A.M., Albert, M.S, Grande L., \& Minaker, K.L. (1994). Performancebased driving evaluation of the elderly driver: safety, reliability, and validity. Journal of Gerontology, 49(4), M153-M159.

Ogawa, T. (1975). Thermal influence on palmar sweating and mental influence on generalized sweating in man. The Japanese Journal of Physiology, 25(4), 525-536.

Ogawa, T., 1993. Pulsatile sweating and sympathetic sudomotor activity. The Japanese Journal of Physiology, 43(3), 275-289.

Ohhashi, T., Sakaguchi, M., \& Tsuda, T. (1998). Human perspiration measurement. Physiological Measurement, 19(4), 449-461.

Ott, B.R., Heindel, W.C., Papandonatos, G.D., Festa, E.K., Davis, J.D., Daiello, L.A., \& Morris, J.C. (2008). A longitudinal study of drivers with Alzheimer's disease. Neurology, 70(14), 1171-1178.

Sagberg, F., Bjørnskau,T. (2006). Hazard perception and driving experience among novice drivers. Accident Analysis and Prevention, 38(2):407-14.

Selander, H., Lee, H.C., Johansson, K., \& Falkmer, T. (2011). Older drivers: On-road off-road test results. Accident Analysis and Prevention, 43(4), 1348-1354.

Siren, A., \& Meng, A. (2012). Cognitive screening of older drivers does not produce safety benefits. Accident Analysis and Prevention, 45, 634-638.

Stein, A.C., \& Dubinsky, R.M. (2011). Driving simulator performance in patients with possible and probable Alzheimer's disease. Annals of Advances in Automotive Medicine/Annual Scientific Conference, 55, 325334.

Smith, S.S., Horswill, M.S., Chambers, B., \& Wetton, M. (2009). Hazard perception in novice and experienced drivers: the effects of sleepiness. Accident Analysis and Prevention, 41(4), 729-33. 
Stutts, J.C., Stewart, J.R., \& Martell, C. (1998). Cognitive test performance and crash risk in an older driver population. Accident Analysis and Prevention, 30(3), 337-346.

Sugishita, M., Hemmi, I., \& JADNI. (2010). Validity and Reliability of the Mini Mental State Examination Japanese (MMSE): A Preliminary Report. Japanese Journal of Cognitive Neuroscience, 12(3•4), 186-190.

Taylor, D.H. (1964). Driver's Galvanic Skin Response and the Risk of Accident. Ergonomics, 7(4), 439-451.

Toyokura, Y., Tanaka, H., Furukawa, T., \& Murakami, K. (1996). Age-related changes of simple cognitive tests for information processing speed-Examination of the paced auditory serial addition task and trail making test in healthy people. Brain Science and Mental Disorders, 7, 401-409, (Japanese).

Venables, P.H., \& Martin, I. (1967). The relation of palmar sweat gland activity to level of skin potential and conductance. Psychophysiology, 3(3), 302-311.

Wetton, M.A., Hill, A., \& Horswill, M.S. (2011). The development and validation of a hazard perception test for use in driver licensing. Accident Analysis \& Prevention, 43 (5), 1759-1770. 